\title{
Heat-Treated Bifidobacterium longum CECT-7347: A Whole-Cell Postbiotic with Antioxidant, Anti-Inflammatory, and Gut-Barrier Protection Properties
}

\author{
Patricia Martorell (D), Beatriz Alvarez (D), Silvia Llopis, Veronica Navarro, Pepa Ortiz, Nuria Gonzalez, \\ Ferrán Balaguer, Antonia Rojas (D), Empar Chenoll (D), Daniel Ramón and Marta Tortajada *
}

check for updates

Citation: Martorell, P.; Alvarez, B.; Llopis, S.; Navarro, V.; Ortiz, P.; Gonzalez, N.; Balaguer, F.; Rojas, A.; Chenoll, E.; Ramón, D.; et al.

Heat-Treated Bifidobacterium longum CECT-7347: A Whole-Cell Postbiotic with Antioxidant, Anti-Inflammatory, and Gut-Barrier Protection Properties Antioxidants 2021, 10, 536. https:// doi.org/10.3390/antiox10040536

Academic Editor: Stanley Omaye

Received: 20 February 2021

Accepted: 24 March 2021

Published: 30 March 2021

Publisher's Note: MDPI stays neutral with regard to jurisdictional claims in published maps and institutional affiliations.

Copyright: (c) 2021 by the authors. Licensee MDPI, Basel, Switzerland. This article is an open access article distributed under the terms and conditions of the Creative Commons Attribution (CC BY) license (https:// creativecommons.org/licenses/by/ $4.0 /)$.
Archer Daniels Midland, Nutrition, Health\&Wellness, Biopolis S.L. Parc Scientific Universitat de València, C/Catedrático Agustín Escardino Benlloch, 9, Paterna, 46980 Valencia, Spain; patricia.martorell@adm.com (P.M.); beatriz.alvarez@adm.com (B.A.); silvia.llopis@adm.com (S.L.); Veronica.NavarroBarrera@adm.com (V.N.); josefa.ortiz@adm.com (P.O.); nuria.gonzalez@adm.com (N.G.); ferran.balaguer@adm.com (F.B.); antonia.rojas@adm.com (A.R.); maria.chenoll@adm.com (E.C.); daniel.ramonvidal@adm.com (D.R.)

* Correspondence: marta.tortajada@adm.com

\begin{abstract}
Non-viable preparations of probiotics, as whole-cell postbiotics, attract increasing interest because of their intrinsic technological stability, and their functional properties, such as immune system modulation, gut barrier maintenance, and protection against pathogens. However, reports on Bifidobacteria-derived postbiotics remain scarce. This study aims to demonstrate the functional properties of a heat-treated (HT), non-viable, Bifidobacterium longum strain, CECT-7347, a strain previously selected for its anti-inflammatory phenotype and ability to improve biomarkers of intestinal integrity in clinical trials. The study used the nematode Caenorhabditis elegans and HT-29 cell cultures as eukaryotic model systems. Our results show that HT-CECT-7347 preserves the capacity to protect against oxidative stress damage, while it also reduces acute inflammatory response and gut-barrier disruption, and inhibits bacterial colonization, by activating pathways related to innate immune function. These findings highlight the interest of the ingredient as a novel postbiotic and pave the way to broaden the range of HT-CECT-7347 applications in gut health.
\end{abstract}

Keywords: Bifidobacterium; postbiotic; probiotic; Caenorhabditis elegans; anti-inflammatory; gut-barrier

\section{Introduction}

Probiotics, defined by the World Health Organization decades ago as live microorganisms that, when administered in adequate amounts, confer a health benefit on the host, and generally understood as beneficial bacteria for host health, are currently widespread in food and beverages, including infant formulas, feed, and nutritional supplements [1-3]. Probiotics have been shown to balance and restore the gut microbiome, confer protection against pathogen infections, modulating immune function, and maintain intestinal barrier integrity, while showing therapeutic and prophylactic potential for a variety of conditions related to gastrointestinal health, but also extra-intestinal disorders, some of which are correlated with gut dysbiosis [4,5].

As greater knowledge is accrued on the mechanisms through which probiotic microorganisms exert their action, a variety of extracellular compounds have been identified as key mediators in the interaction with the host, including organic acids, antimicrobial compounds and enzymes [5]. In addition, cell-envelope related components, such as lipoteichoic acids, exopolysaccharides, or peptidoglycan-derived molecules, have been shown to trigger biological activities attributed to their parent probiotic microorganisms [6-8].

By extension, non-viable, generally heat-treated probiotic microorganisms have been shown to exert anti-inflammatory, immunomodulatory, antioxidant, and antimicrobial activities in vitro, ex vivo, and in vivo $[9,10]$. Jointly known as postbiotics, probiotic subcellular fractions, and non-living preparations are gathering interest both from the scientific 
and industrial sectors. Due to their intrinsic higher stability in comparison to their living counterparts, postbiotics facilitate technological applications, and supply chain logistics, enabling delivery in challenging food matrices, and extreme climate conditions, where probiotic survival is compromised [11-13]. Postbiotics have also shown promise in a variety of clinical settings, including medical foods and infant nutrition [7]. Furthermore, some safety concerns have been raised on the use of live strains in potentially vulnerable groups, such as immune-suppressed patients, again highlighting the interest in exploring the functional effects of postbiotics [14].

Bifidobacterium longum CECT-7347 is a probiotic strain isolated from a healthy breast-fed infant, that has been shown in different models to promote anti-inflammatory effects, including the reduction of IFN- $\gamma$ and TNF- $\alpha$ and increased IL-10 production in human peripheral blood mononuclear cells. Moreover, the reduction of pro-inflammatory markers and increased IL-10 production in monocyte derived dendritic cells, together with an increased expression of zonulin, has also been demonstrated $[15,16]$. In a clinical trial conducted in children with newly diagnosed celiac disease, typically affected by intestinal inflammation, dysbiosis, and altered intestinal structure, the consumption of the strain resulted in greater height, decreased peripheral lymphocytes, and reduced TNF- $\alpha$ in the CECT-7347 group [17]. In a pilot study on non-celiac gluten sensitivity, the combination of diet and CECT-7347 resulted in the improvement of digestive and extra-intestinal symptoms [18]. Due to its anti-inflammatory/anti-oxidant profile, this strain has also been used in probiotic formulations shown to improve symptomatology derived from atopic dermatitis, psoriasis, and asthenozoospermia, conditions which are related to damaged intestinal integrity [19-22]. In this context, the purpose of this research is to establish whether the probiotic properties of B. longum CECT-7347 are preserved in its heat-treated, non-viable form. Many in vitro and in vivo approaches have been used to characterize the functional effects of probiotics. Among the different animal models available, the small nematode Caenorhabditis elegans is particularly interesting because it feeds on bacteria, and is also advantageous given its simplicity, transparency, and ease of cultivation. This nematode has a well-defined anatomy, a rapid reproductive cycle and short lifespan. C. elegans is also becoming a genetic model for the molecular identification of many key genes in different cell processes [23]. These advantages have made C. elegans an ideal model for characterizing ingredients with antioxidant activity and identifying new antioxidant probiotic strains [24].

Accordingly, we have undertaken a study to evaluate the properties of HT-CECT7347 compared to its parental strain, utilizing C. elegans as a model system. Complementary experiments have been performed in HT-29 cells-a human colon cancer-derived cell line extensively used in biological research, for its capacity to form tight monolayers and its similarity to enterocytes, in the small intestine-with the objective of investigating the capacity of B. longum HT-CECT7347 to protect against oxidative stress, modulate pro-inflammatory mediators and gut-barrier integrity, together with pathogen colonization. Our study provides further evaluation of postbiotics for digestive and immune health applications.

\section{Materials and Methods}

\subsection{Bacterial Strains and Culture Conditions}

Bifidobacterium longum CECT-7347 was isolated from the feces of a healthy infant as described elsewhere [25]. Bacterial cultures were grown in Man-Rogosa-Sharpe (MRS) medium agar and broth supplemented with $0.05 \%(w / v)$ cysteine and kept at $37^{\circ} \mathrm{C}$ in anaerobic conditions for $24 \mathrm{~h}$. For heat inactivation, cells were harvested by centrifugation and washed twice with saline solution and adjusted at stock concentration of $2 \times 10^{9}$ cells $/ \mathrm{mL}$. Afterwards, adjusted cultures were treated by autoclaving treatment at $121^{\circ} \mathrm{C}, 1 \mathrm{bar}$, during $20 \mathrm{~min}$. Staphylococcus aureus (ATCC25923) was cultured on tryptic soy broth (TSB) aerobically. Salmonella enterica subsp. enterica serovar Typhimurium ATCC 14028 was grown on Luria-Bertani (LB) medium. Both pathogenic strains were grown overnight at $37^{\circ} \mathrm{C}$ in aerobic conditions. For Caenorhabditis elegans killing assays, overnight cultures were diluted in fresh TSB (S. aureus) or fresh LB (S. typhimurium) and seeded on NGM agar plates at a final dose of $10^{8} \mathrm{cfu} /$ plate. The plates were incubated aerobically at $37^{\circ} \mathrm{C}$ for $18 \mathrm{~h}$. 


\subsection{Cell Cultures}

Human colonic epithelial cells (HT-29) were acquired from the American Type Culture Collection (ATCC, Rockville, MD, USA). Cells were cultured as monolayers in a $37^{\circ} \mathrm{C}$ humidified atmosphere with $5 \% \mathrm{CO}_{2}$. The cells were cultured in McCoy's $5 \mathrm{~A}$ with $10 \%$ heatinactivated fetal bovine serum (FBS) containing $100 \mu \mathrm{g} / \mathrm{mL}$ streptomycin and $100 \mathrm{IU} / \mathrm{mL}$ penicillin.

\subsection{Cell Treatment and Viability Determinations}

HT-29 cells were seeded at $1.5 \times 10^{6}$ cells/well (6-well plates). After complete confluence had been reached, HT-CECT-7347 and TNF- $\alpha(4 \mathrm{ng} / \mathrm{mL})$ were added to HT-29 cells in complete medium (McCoy's 5A, 10\% FBS and antibiotics) for $16 \mathrm{~h}$. Cell viability was determined with 3-(4,5-dimethylthiazol-2-yl)-2,5-diphenyltetrazolium bromide (MTT) assay (Abcam).

\subsection{Expression of Pro-Inflammatory Cytokines}

IL-8 concentrations in culture medium were quantified using an enzyme-linked immunosorbent assay (ELISA) kit in HT-29 human colonic epithelial cells, performed according to manufacturer instructions (Abcam).

\subsection{Western Blotting}

For Western Blotting, cells were lysed with lysis buffer (50 mM Hepes, $150 \mathrm{mM} \mathrm{NaCl}$, $1 \%$ Triton X-100) including phosphatase and protease inhibitors (1 $\mathrm{mM}$ phenylmethylsulfonyl fluoride, $10 \mu \mathrm{g} / \mathrm{mL}$ leupeptin, $10 \mu \mathrm{g} / \mathrm{mL}$ aprotinin, $1 \mathrm{mM}$ sodium ortovanadate, $5 \mathrm{mM} \mathrm{NaF}, 100 \mu \mathrm{M}$ TPCK, $1 \mathrm{mM}$ AEBSF, $10 \mu \mathrm{M} \mathrm{E}-64,5 \mathrm{mM}$ phenanthroline, and $20 \mu \mathrm{g} / \mathrm{mL}$ pepstatin) on ice for $20 \mathrm{~min}$. After centrifugation at $12,000 \times \mathrm{g}$ for $20 \mathrm{~min}$, the protein concentration in the supernatant (cytosolic extract) was determined. Pellets were subjected to a second extraction with a nuclear lysis buffer $(20 \mathrm{mM}$ Tris- $\mathrm{HCl}, \mathrm{pH} 8,137 \mathrm{mM} \mathrm{NaCl}$, $1 \mathrm{mM} \mathrm{MgCl}_{2}, 1 \mathrm{mM} \mathrm{CaCl}_{2}, 10 \%$ glycerol, $1 \%$ NP-40, $0.5 \%$ sodium deoxycholate, $0.1 \%$ SDS) including phosphatase and protease inhibitors (same as above). Protein samples were subjected to 7.5 or $12 \%$ sodium dodecyl sulfate-polyacrylamide gel electrophoresis and transferred to polyvinylidene difluoride membranes (BioRad, Hercules, CA, USA). The membranes were blocked with TBS (10 mM Tris (pH 7.4), $100 \mathrm{mM} \mathrm{NaCl}$, and $0.5 \%$ Tween 20) containing $5 \%$ bovine serum albumin (BSA) for 4 hours at room temperature and incubated with anti-NFKB/p65 (1:1000, Abcam), zonulin (1:1000, Thermo) or tubulin (1:5000, Abcam) antibodies overnight at $4{ }^{\circ} \mathrm{C}$. Then, the membranes were incubated with horseradish peroxidase (HRP) with conjugated anti-rabbit-immunoglobulin G (IgG) (1:10,000, Abcam). The membranes were visualized by enhanced chemiluminescence (ECL-prime, BioRad) and detected using a Bio imaging system (ImageQuant LAS 500, GE Healthcare). Images were quantified by Image Studio software (LI-COR Biosciences, Lincoln, NE, USA).

\subsection{Immunofluorescence}

Immunofluorescence assays were conducted to analyze the translocation of zonulin, where HT-29 cells were seeded on cover slips at $3 \times 10^{5}$ cells $/$ well (24-well plates). After complete confluence had been reached, HT-CECT-7347, and TNF- $\alpha(4 \mathrm{ng} / \mathrm{mL})$ were added to HT-29 cells for $16 \mathrm{~h}$. After treatment, cells were fixed with formaldehyde $4 \% v / v$ for $10 \mathrm{~min}$ at $4{ }^{\circ} \mathrm{C}$ and then permeabilized with $0.25 \%$ Triton-X100 for $10 \mathrm{~min}$. Next, the cells were blocked with $2 \% w / v$ bovine serum albumin in PBST + glycine. The samples were incubated with zonulin $\left(5 \mu \mathrm{g} / \mathrm{mL}\right.$, Thermo) antibodies at $4{ }^{\circ} \mathrm{C}$ overnight, followed by incubating with an AlexaFLuor488-conjugated goat anti-rabbit (1:1000, Abcam) for $2 \mathrm{~h}$ at room temperature. Fluoroshield medium with DAPI (Abcam) was used for visualization of nucleus. The stained cells were examined by confocal laser scanning microscope (FV1000, Olympus, in the microscopy section of the SCSIE at the University of Valencia). 


\subsection{Caenorhabditis elegans Strains and Maintenance Conditions}

Caenorhabditis elegans strains N2, Bristol (wild-type) and the mutant strain GR1307, daf-16 ( $m g D f 50)$ were obtained from the Caenorhabditis Genetics Center at the University of Minnesota and maintained at $20^{\circ} \mathrm{C}$ on Nematode Growth Medium (NGM) plates with Escherichia coli strain OP50 as normal diet for nematodes.

\subsection{Lifespan Assays in C. elegans}

To measure the lifespan of $C$. elegans, synchronized worms of the wild-type strain (N2) and the mutant strain GR1307 (daf-16) were grown at $20^{\circ} \mathrm{C}$ until they reached the young adult stage. Worms were then transferred to NGM agar plates covered with lawns of E. coli OP50 or B. longum CECT-7347. For heat-treated CECT-7347, culture was adjusted and added to the agar surface at three final doses $\left(10^{8}, 10^{9}, 10^{10}\right.$ cells $\left./ \mathrm{mL}\right)$. The plates were incubated at $20^{\circ} \mathrm{C}$ and the numbers of live and dead worms were scored until $100 \%$ population was dead. Two independent assays were carried out with each cell concentration and strain.

\subsection{Oxidative Stress Resistance in Caenorhabditis elegans}

Caenorhabditis elegans wild-type strain N2 and the mutant strain GR1307, daf-16 (mgDf50) were egg-synchronized in NGM plates (control medium) and NGM plates containing CECT7347 or HT-CECT-7347 at final dose of $10^{8}$ cells/plate. Nematode viability was assessed after oxidative stress $\left(2 \mathrm{mM} \mathrm{H}_{2} \mathrm{O}_{2}\right)$ as described elsewhere [26]. Vitamin $\mathrm{C}(10 \mu \mathrm{g} / \mathrm{mL})$ was used as positive control. Experiments were carried out in duplicate.

\subsection{Infection Assays in C. elegans}

Infection assays were performed as described elsewhere, with some modifications [27-29]. Nematodes of the wild-type strain (N2) were age-synchronized by recovering the eggs from adults in agar plates, already seeded with E. coli OP50 (NGM), and NGM plates containing either CECT-7347 or HT-CECT-7347, at a dose of $10^{8}$ cells/plate. Once the worms reached the young adult stage, they were transferred to the infection plates containing a lawn of the pathogen (S. aureus ATCC 25923 or S. enterica subsp. enterica serovar Typhimurium ATCC 14028). A condition without infection (NGM medium with the strain E. coli OP50) and a condition of infection only with the corresponding pathogen were included. Afterwards, nematodes were incubated at $25^{\circ} \mathrm{C}$ in the different conditions and scored for survival during 5-10 days. Worms were counted as alive or dead individuals by gentle touching with a platinum wire.

\subsection{Evaluation of Gut Barrier Integrity in C. elegans}

Age-synchronized nematodes of the wild-type strain N2 were obtained and maintained in NGM plates or NGM plates supplemented with the strain CECT-7347 or HT-CECT-7347 strain $\left(10^{7}\right.$ and $10^{8}$ cells/plate) at $20^{\circ} \mathrm{C}$. To induce intestinal permeability L4-larvaes were exposed to methotrexate (MTX $0.1 \mu \mathrm{g} / \mathrm{mL}$ ) for $24 \mathrm{~h}$ (acute exposure). A condition without damage was also included. To evaluate the intestinal permeability in MTX exposed-nematodes, Nile Red staining $(0.05 \mu \mathrm{g} / \mathrm{mL})$ was used [30]. A total of 30 worms were randomly selected from each condition and observed in a fluorescence stereomicroscope Nikon SMZ18, equipped with NIS-ELEMENT image software. Results are shown as the percentage of fluorescence in each treatment with respect the MTX-treated nematode population.

\subsection{Statistical Analysis}

All the statistical analyses were performed with GraphPad Prism 4 software. Data were expressed as the mean \pm standard deviation and analyzed by one-way ANOVA, using a Tukey's multiple comparison post-hoc test. A probability value of 0.05 was considered statistically significant. Survival curves were analyzed using the log Rank T-test significance test, provided by GraphPad Prism 4. 


\section{Results}

\subsection{Antioxidant Effect of Bifidobacterium Longum CECT-7347 and Its Heat-Treated Version, in} Caenorhabditis elegans

Probiotic strains (live and heat treated cells) exert antioxidant activity, reducing damage caused by oxidative stress [31-34]. Moreover, previous studies have demonstrated that probiotics strains are able to exert antioxidant effect on the nematode C. elegans [35-37]. Therefore, to confirm the antioxidant properties of the heat-treated B. longum HT-CECT7347 strain, while comparing them to those exerted by the viable CECT-7347 strain, we used the in vivo model C. elegans. Nematodes of the wild-type N2 strain were fed with the heat-treated CECT-7347 or the live cells, and their survival rate after acute oxidative stress with hydrogen peroxide was compared to control-fed nematodes (NGM with E. coli OP50). As reference, survival of nematodes without oxidative stress was included. Results indicate a similar survival under the different feeding conditions in non-stressed nematodes. However, nematodes treated with strain HT-CECT-7347 were more resistant to oxidative stress with $\mathrm{H} 2 \mathrm{O} 2$ than control-fed nematodes ( $57 \%$ vs. $27.5 \%$ of survival value) $(p \leq 0.001)$ (Figure 1). Moreover, this activity was similar to that observed in CECT-7347 live cells, thus demonstrating that the heat-treated cells still preserve the ability to protect in vivo against acute oxidative stress.

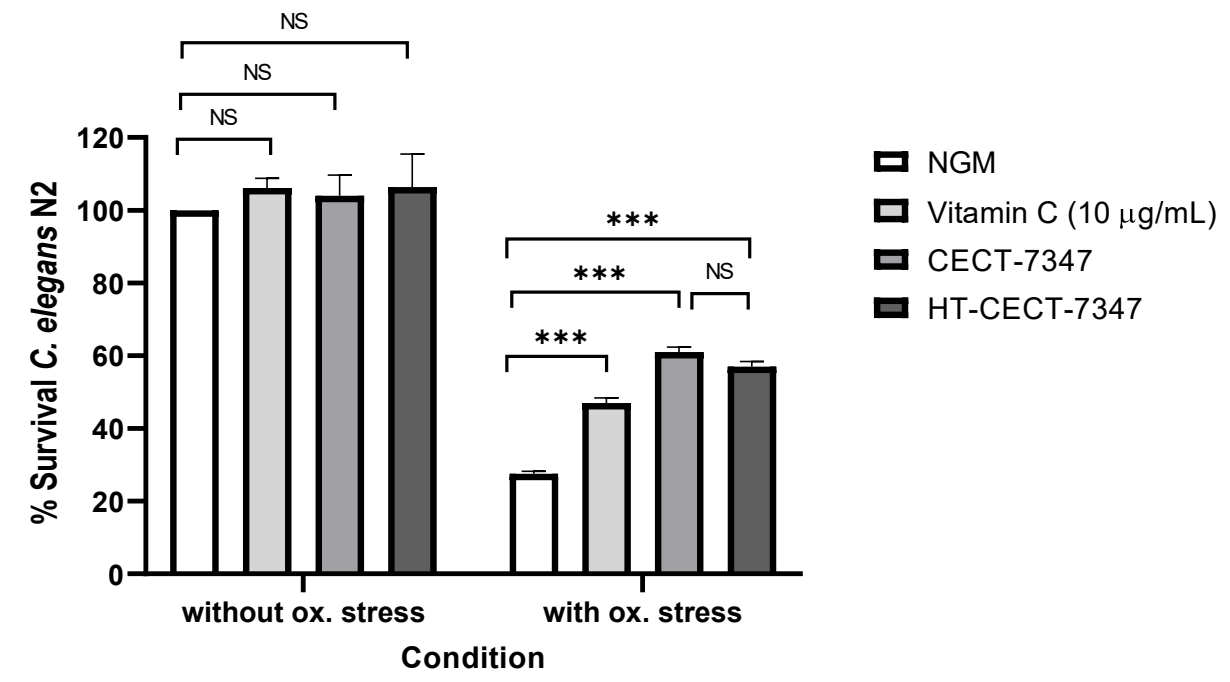

Figure 1. Survival of C. elegans (N2) fed with B. longum CECT-7347 or HT-CECT-7347 without oxidative stress and after acute oxidative stress. NGM: Nematode growth medium used as control feeding condition. ${ }^{* *}$ Significant $p<0.001$; NS: No significant differences. One-way ANOVA was applied. Data are the average of two independent experiments ( $n=200 /$ condition).

Furthermore, to examine the mechanisms underlying this functional effect, we repeated the experiments in a C. elegans mutant strain, daf-16. This strain was fed with CECT-7347 and HT-CECT-7347 and subjected to acute oxidative stress. DAF-16 codes for the Forkhead family of transcription factors (FOXO) and plays a central role in mediating the molecular mechanisms triggered by the insulin-like signaling pathway (IIS). This pathway regulates ageing, immunity, and lipid metabolism in C. elegans [38,39]. Results indicated that feeding DAF-16 mutant worms with HT-CECT-7347 or CECT-7347 did not increase worm survival rates, suggesting that the mechanism of the strain (both live and heat-treated cells) is dependent on DAF-16 (Figure 2). By contrast, vitamin C activity was independent of DAF-16, as significant survival was observed in the mutant strain.

Previous studies have correlated a strengthened resistance to oxidative stress in C. elegans with lifespan extension in response to the consumption of probiotic strains $[35,40]$. Caenorhabditis elegans represents a suitable model organism for ageing studies as it can be easily grown on agar plates, fed with bacteria or yeast, and its lifespan is modulated by genetic, and environmental factors [41]. Moreover, genetic pathways such as IIS [42] and 
p38 mitogen-activated protein kinase (p38 MAPK) [43] pathways involved in life extension are evolutionarily conserved. Indeed, different probiotic strains have been shown to have pro-longevity effects in the nematode [44].

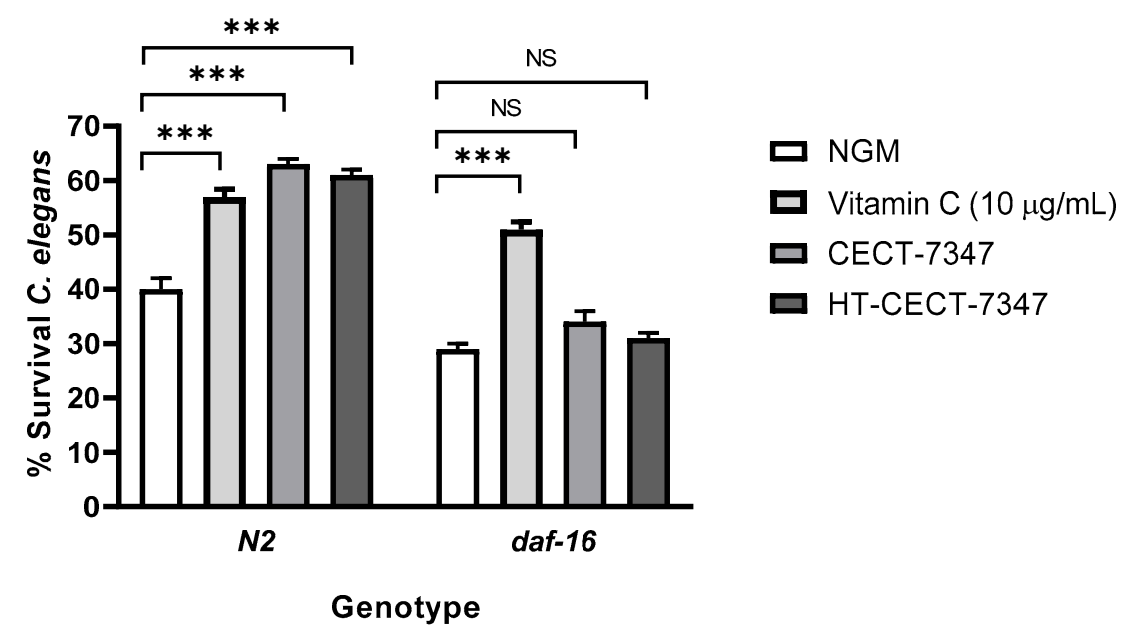

Figure 2. Survival of C. elegans mutant strain in DAF-16 fed with B. longum CECT-7347 or HT-CECT7347 after acute oxidative stress. NGM: Nematode growth medium used as control feeding condition. *** Significant $p<0.001$; NS: No significant differences. One-way ANOVA was applied. Data are the average of two independent experiments ( $n=200 /$ condition).

To gain a better understanding of the properties of the strain and its heat-treated counterpart, we analyzed the effect of both CECT-7347 and HT-CECT-7347 on C. elegans lifespan. As shown in Figure 3a, the living strain significantly improved lifespan $(p<0.0001)$, and an increase of 5-6 days in mean lifespan was observed compared with control NGM. Conversely, the heat-treated form HT-CECT-7347, preserved, but did not extend, worm's viability. This result indicates that this form of the strain is not harmful for C. elegans. Additionally, the results would suggest a mechanism for lifespan extension dependent on cell viability, is probably related to the production of a specific metabolite.

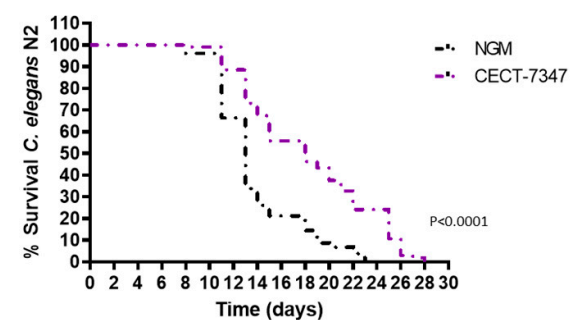

(a)

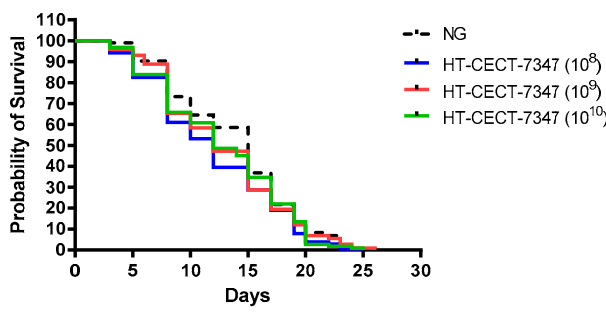

(b)

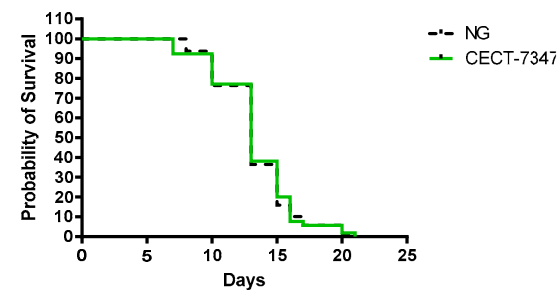

(c)

Figure 3. Effect of the strain CECT-7347 and HT-CECT-73 47 on C. elegans lifespan. (a) B. longum CECT-7347 significantly increases lifespan of C. elegans wild-type strain (N2) (b) Cells of HT-CECT-7347 do not increase C. elegans (N2) lifespan (dose $10^{8}, 10^{9}$, and $10^{10}$ cells/plate) (c) Lifespan increase by B. longum CECT-7347 is lost in the C. elegans in DAF-16 (GR1307) mutant strain. Curve comparisons vs. E. coli OP50 are indicated ( $p$-values). Log Rank T-test was applied. Data correspond to the average of two independent assays ( $n=200 /$ condition).

Furthermore, we analyzed whether the CECT-7347-related increase in lifespan was dependent on DAF-16. It is well known that daf-16 is a regulator of the inflammatory response, via a pathway that is well conserved in humans [35]. Therefore, we evaluated the effect of CECT-7347 on C. elegans daf-16 mutant strain. A loss of the protective effect in the daf-16 mutant was determined (Figure 3b), suggesting that the pro-longevity effects of CECT-7347 are dependent on the daf-16 pathway. 
3.2. Anti-Inflammatory Properties of B. Longum HT-CECT-7347 in HT-29 Cells: Suppressive Effect on Pro-Inflammatory Cytokines and NF- $\kappa B$ Activation

Probiotics capable of alleviating oxidative stress in C. elegans, via the DAF16 transcriptional factor, have been shown to present an anti-inflammatory profile when co-cultured with HT-29 cells, stimulated by pro-inflammatory cytokines [35]. Therefore we hypothesized that, owing to its anti-oxidant characteristics, heat-treated CECT-7347 could down-play the production of pro-inflammatory cytokines upon TNF- $\alpha$ stimulation. TNF- $\alpha$ triggers inflammatory responses and develops inflammation by inducing the expression of proinflammatory cytokines, including IL-1 $\beta$, IL-6, and IL-8.

The human epithelial cell line HT29 has previously been described as having the ability to produce the chemokines IL-8, Gro $\alpha$, macrophage inflammatory protein 1, and RANTES upon stimulation with IL-1, TNF- $\alpha$, and interferon $\gamma[45,46]$. In order to assess the antiinflammatory properties of HT-CECT-7347, IL-8 production was evaluated by incubating HT29 cell monolayers with TNF- $\alpha$ in the presence of HT-CECT-7347. As shown in Figure 4, the stimulation of HT29 cells with TNF- $\alpha$ followed by co-incubation with HT-CECT-7347 resulted in a significant dose-dependent decrease in IL-8 production, without significantly affecting its viability (Figure A1). Concentrations equivalent to $10^{10}$ and $10^{9}$ cells $/ \mathrm{mL}$ of HT-CECT-7347 reduced the secretion of IL- 8 by $73.8 \%(743 \pm 111 \mathrm{pg} / \mathrm{mL})$ and $27.0 \%$ $(2066 \pm 101 \mathrm{pg} / \mathrm{mL})$, respectively.

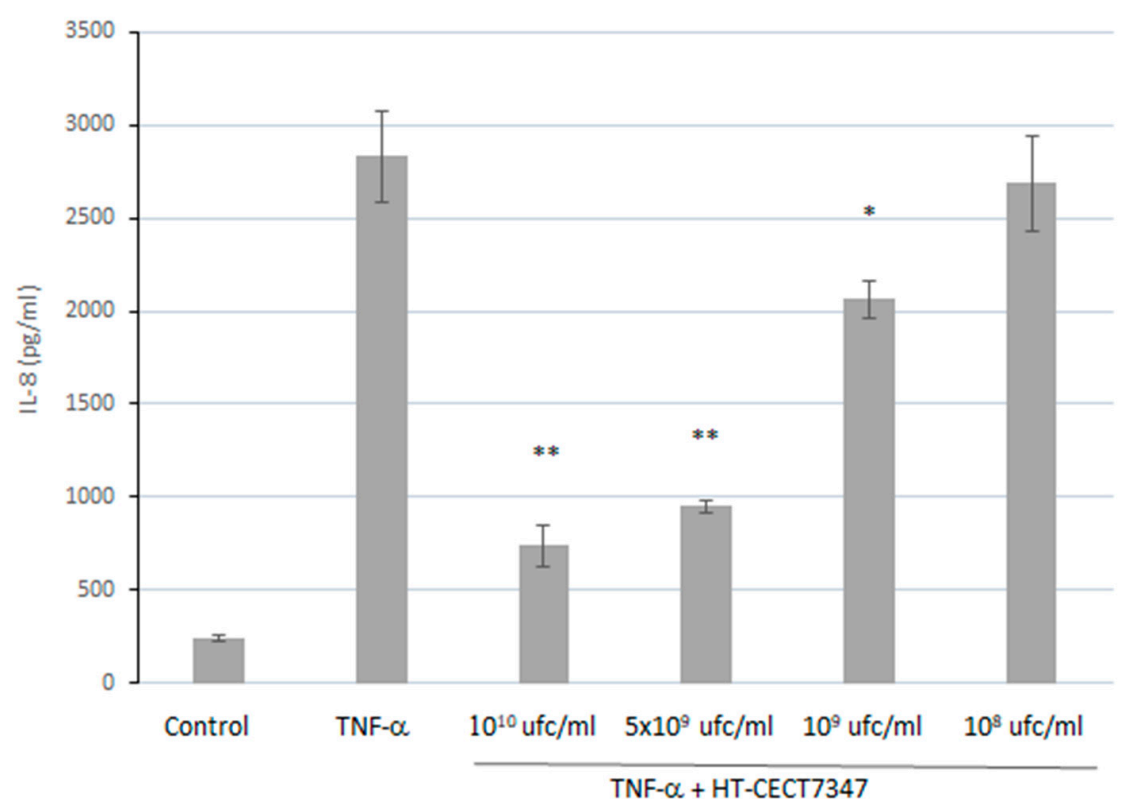

Figure 4. Quantification of IL-8 secretion by HT-29 cells incubated with HT-CECT-7347 and stimulated with TNF- $\alpha$. Data are given as means and standard deviation $(n=2)$. ${ }^{*}{ }^{* *}$ indicates significantly lower than TNF- $\alpha$ control $(p<0.05$ and $p<0.01$, respectively).

Moreover, NF- $\kappa \mathrm{B}$ plays a key role in regulating cytokine expression levels following a proinflammatory stimulus [45]. In the absence of stimulus, NF-kB is maintained in its inactive form in the cytosol associated with the inhibitory protein IkB. Upon receipt of a proinflammatory stimulus, such as TNF- $\alpha$, translocation of several adapters to the cytoplasmic membrane occurs, such as TNF receptor-associated death domain protein (TRADD), receptor-interacting protein (RIP) and TNF receptor-associated factor 2 (TRAF2), which activates the IkB-kinase (IKK) complex [46]. NF-kB p50-p65 heterodimer proteins are released after phosphorylation of inhibitory $\mathrm{kB}$ (IkB) molecules by IKK, migrate to the cell nucleus and bind to specific $\mathrm{kB}$ sites, leading to transcriptional activation of genes coding for cytokines and chemokines, cell adhesion molecules, and immunoreceptors, all of which are important mediators of the inflammatory response [47-50]. 
Therefore, we evaluated whether the inhibitory effects of HT-CECT-7347 on the proinflammatory cytokines were due to its ability to suppress TNF- $\alpha$-induced NF- $\kappa \mathrm{B}$ activation. With this purpose, we examined NF-kB-p65 subunit localization after HT-CECT-7347 treatment in TNF- $\alpha$-induced HT-29 cells by Western blot, results shown in Figure 5. Compared to the TNF- $\alpha$ individual treatment, HT-CECT-7347 and TNF- $\alpha$ co-treatment decreased NF-kB-p65 nuclear localization and increased NF-kB-p65 expression in the cytosol.
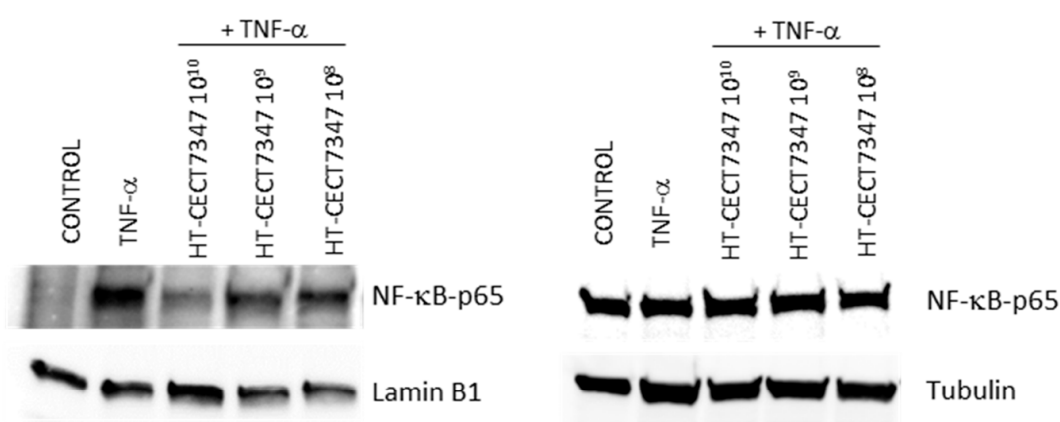

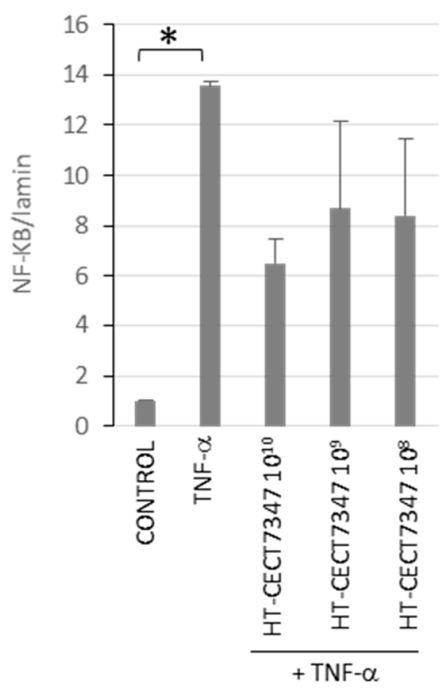

(a)

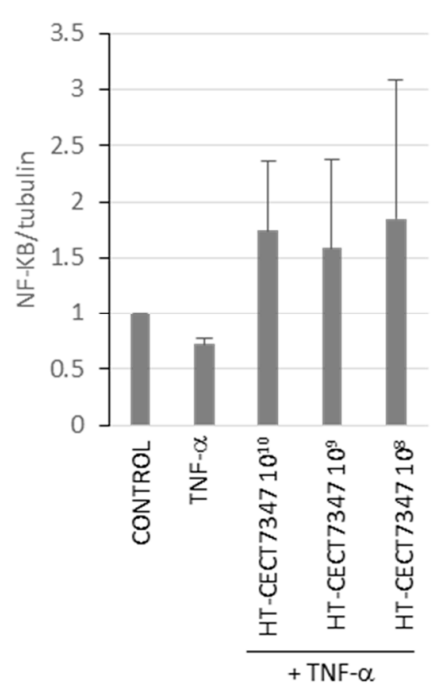

(b)

Figure 5. Analysis of the effect of HT-CECT-7347 on TNF- $\alpha$-induced nuclear translocation of NF-kB p65 subunit in HT-29 cells. Western blot analysis for NF-kB-p65 subunit levels in nuclear (a) or cytosolic (b) fractions of HT-29 cells treated with TNF- $\alpha$ with or without HT-CECT-7347. Expression results were quantified by Image Studio software (LI-COR Biosciences) and represented as a graph. Data represents the means $(+/-\mathrm{SD})$ of two independent experiments. ${ }^{*}$ indicates significantly higher than control $(p<0.05)$.

\subsection{Gut Barrier Protection and Inhibition of Bacterial Colonization Capacity}

Epithelial barrier integrity and exchange between bloodstream and intestinal lumen is regulated by tight junctions (TJ), protein structures that constitute the major barriers sealing paracellular spaces between epithelial cells. Zonulin, a protein released by intestinal epithelial cells, acts as a TJ modulator. Probiotic strains have been shown to exert beneficial effects on intestinal barrier function, modulating tight junction proteins and zonulin expression [51,52]. Previous studies have reported the beneficial effect of CECT7347 on intestinal permeability [15]. Since gut-barrier disruption can lead to endotoxemia, triggering an inflammatory response and resulting in increased susceptibility to infection, we investigated whether CECT-7347 and HT-CECT-7347 could provide a protective effect on TJ, while inhibiting bacterial colonization. 


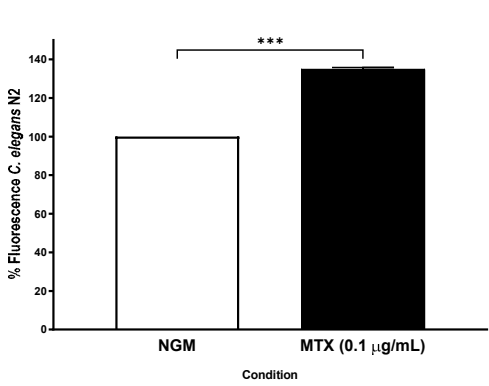

(a)

NGM (control)

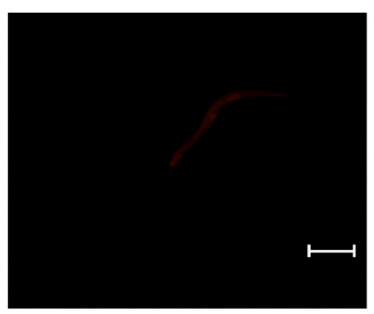

NGM (control)

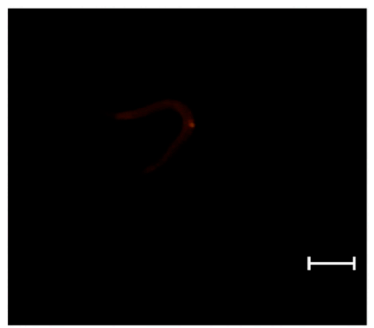

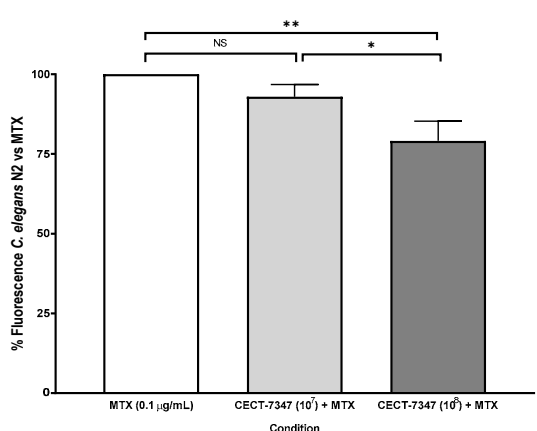

(b)

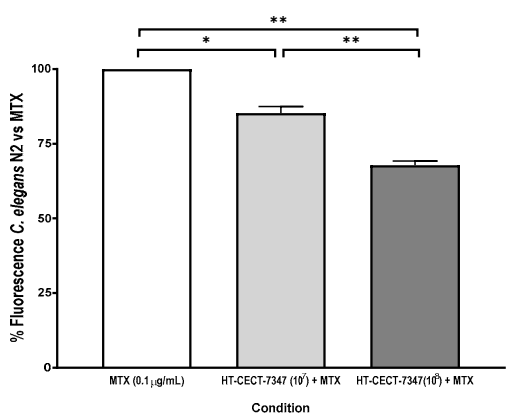

(c)

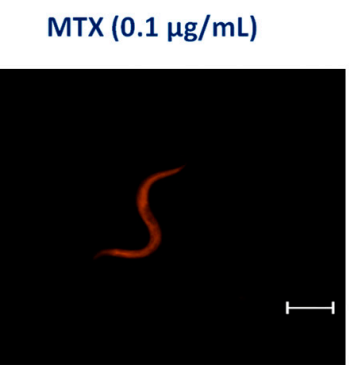

$\operatorname{MTX}(0.1 \mu \mathrm{g} / \mathrm{mL})$

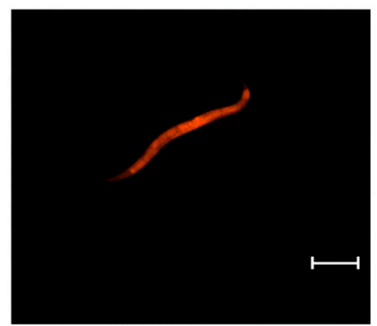

CECT7347 $\left(10^{7}\right)+\mathrm{MTX}$

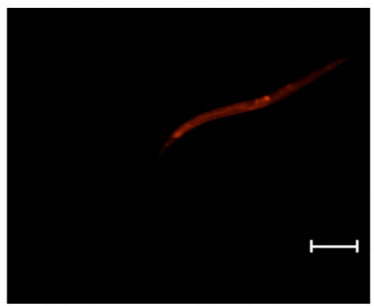

HT-CECT-7347 $\left(10^{7}\right)+$ MTX

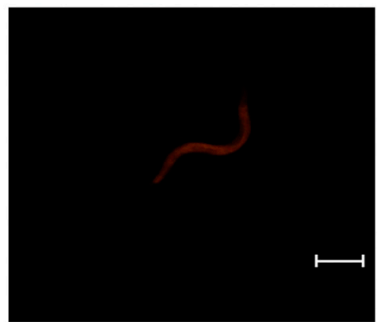

CECT7347 $\left(10^{8}\right)+\operatorname{MTX}$

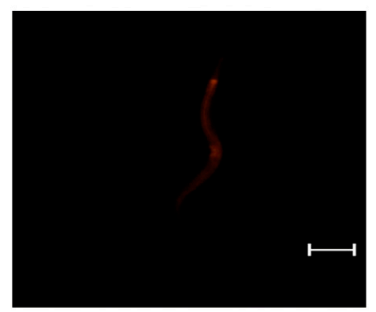

HT-CECT7347 $\left(10^{8}\right)+$ MTX

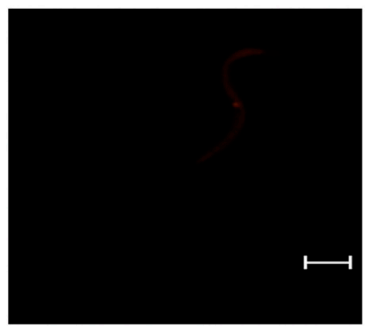

(d)

Figure 6. (a) Percentage of fluorescence intensity of Nile Red in worms without gut damage (NGM condition) or in worms with MTX-induced intestinal damage at dose of $0.1 \mu \mathrm{g} / \mathrm{mL}$. Data are the average of two independent experiments ( $n=60$ /condition); (b) Percentage of fluorescence of worms treated with MTX at $0.1 \mu \mathrm{g} / \mathrm{mL}$ (gut damage condition) with CECT-7347 or (c) with HT-CECT-7347 at two different doses $\left(10^{7}\right.$ and $10^{8}$ cells $)+$ MTX $(0.1 \mu \mathrm{g} / \mathrm{mL})$. Values are the average of two independent assays. ( $n=60 /$ condition). ${ }^{* * *}$ Significant at $p$-value $\leq 0.001$. ${ }^{* *}$ Significant at $p$-value $\leq 0.01 ;{ }^{*}$ Significant at $p$-value $\leq 0.05$. NS: No significant differences. One-way ANOVA was applied. (d) Representative images of Nile Red staining in live young adult C. elegans in a wild-type N2 animal under fluorescence microscopy. Worms treated with MTX to induce intestinal damage were fed with CECT-7347 or HT- CECT-7347 strain at two doses (10 $70^{7}$ and $10^{8}$ cells). Scale bar $250 \mu \mathrm{m}$. Original image taken by the authors for this paper with a Nikon-SMZ18 fluorescence stereomicroscope.

To investigate their efficacy in preventing leaky gut, worms were fed with CECT-7347 and HT-CECT-7347, and treated with MTX to alter nematode intestinal permeability. Drugs with MTX have been used to treat autoimmune diseases and cancer, and their intestinal toxicity has been described in humans and mice (Huang et al., 2020). Firstly, we determined that MTX-exposed nematodes significantly enhanced fluorescence intensity of Nile Red compared to control nematodes (NGM plates without MTX) (Figure 6a) (increase of 35.1\%) showing an alteration in intestinal permeability in C. elegans, as previously reported for other toxins [53] and also shown for MTX in mice and rats [54,55]. [54,55]. By contrast, pre-treatment with the heat-treated probiotic HT-CECT-7347 or CECT-7347 blocked the increase in fluorescence intensity by Nile Red staining (Figure 6b). Representative images of nematodes in each condition, obtained by fluorescence microscopy, are shown in Figure 6d. A significant reduction in the fluorescence intensity at both doses analyzed $\left(10^{7}\right.$ and $10^{8}$ 
cells) fed with HT-CECT-7347 was observed in MTX-treated nematodes, being $10^{8} \mathrm{CFU}$ dose the most effective ( $32.1 \%$ reduction, $p$-value $\leq 0.01$ ). In the case of the live cells, only the dose of $10^{8}$ cells was significant in reducing fluorescence. These results would suggest that HT-CECT-7347, and to a lesser extent CECT-7347, help in maintaining intestinal permeability in MTX-exposed nematodes.

In order to confirm a TJ-mediated effect, zonulin (ZO-1) in HT-29 monolayers was analyzed with immunofluorescence to determine whether B. longum HT-CECT-7347 could affect the localization and level of zonulin on the apical surface of adjacent HT-29 cell membranes during inflammation. As shown in Figure 7a, immunofluorescence analysis of control cells showed the presence of a continuous line at the contact points of the cells, which was fragmented after treatment with TNF- $\alpha$. Conversely, when cell cultures were co-treated with HT-CECT-7347 and TNF- $\alpha$, immunofluorescence showed a pattern similar to that of the control. Moreover, Western blot analysis revealed that HT- CECT-7347 counteracted the TNF- $\alpha$-induced hypoexpression of ZO-1 (Figure 7b).

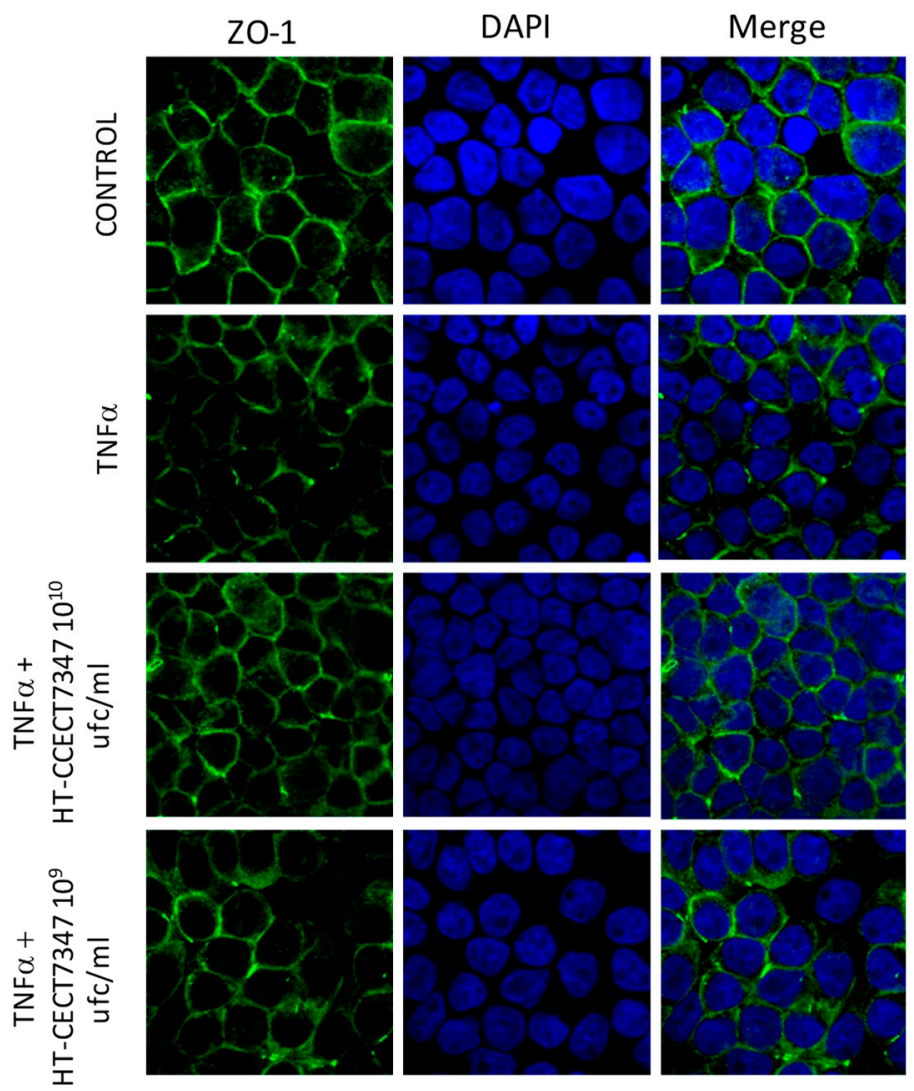

(a)
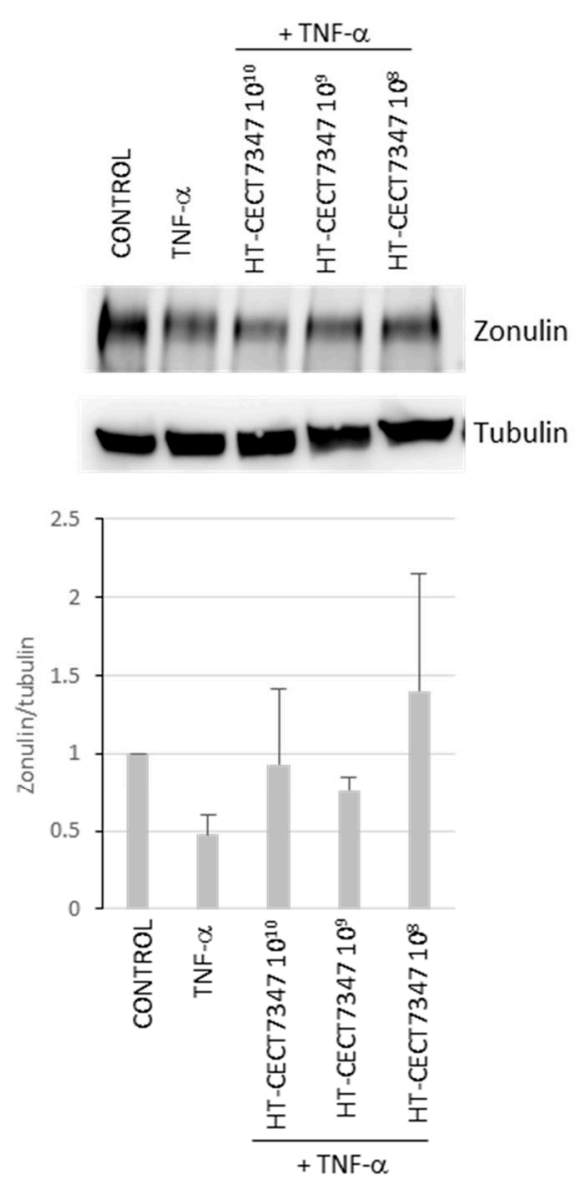

(b)

Figure 7. Analysis of the effect of HT-CECT-7347 on zonulin localization on TNF- $\alpha$-stimulated in HT-29 cells. (a) Representative images from immunofluorescence analysis of zonulin (green fluorescence AlexaFluor 488) in TNF- $\alpha$ stimulated cells show a significant decrease in staining of ZO-1. Localization of ZO-1 is not affected when cells are stimulated by TNF- $\alpha$ in the presence of HT-CECT-7347. Micrographs were captured at $60 \times$ magnification. (b) Western blot analysis for zonulin levels in cell extracts of HT-29 cells treated with TNF- $\alpha$ with or without HT-CECT-7347. Expression results were quantified by Image Studio software (LI-COR Biosciences) and represented as a graph. Data represents the means (+/ - SD) of two independent experiments.

To further explore the potential of the strain in the context of digestive malfunction, we investigated whether CECT-7347 and/or HT-CECT-7347 were protective against bacterial 
infection. Caenorhabditis elegans has been reported as a host for several human pathogens such as S. enterica subsp. enterica serovar Typhimurium and S. aureus [56-58] and it is being used as an alternative to traditional mammalian pathogenesis models [59]. Salmonella causes persistent infection in the intestine of $C$. elegans, resulting in early death of infected animals, while $S$. aureus does not persistently colonize the digestive tract of nematodes but ultimately leads to worm death [58]. We explored whether CECT-7347 and HT-CECT-7347 increased C. elegans defenses against pathogens by exposing them to the probiotic cells in agar-based killing assays with Salmonella or S. aureus.

As shown in Figure 8a, S. aureus-infected nematodes under control-feeding condition reduced viability in a few days, reaching $80 \%$ mortality at day 3 , and $100 \%$ at day 5 . Conversely, nematodes fed with the probiotic CECT-7347 or its heat-treated form HT-CECT-7347 significantly increased in survival $(p<0.0001)$, maintaining around $70 \%$ of survival at day 3 and $50 \%$ of survival at day 5 . In the case of S. enterica subsp. enterica serovar Typhimurium CECT 4594, results indicated the efficacy of the pathogen to infect and provoke mortality in C. elegans during days 6 and 9 of infection (Figure 8b). The exposure of nematodes to CECT-7347 or HT-CECT-7347 resulted in a significant increase in viability $(p<0.0001)$, with $80 \%$ of survival at day 8 (vs. $50 \%$ in control-fed nematodes), and $70 \%$ of survival (vs. $100 \%$ in control conditions).

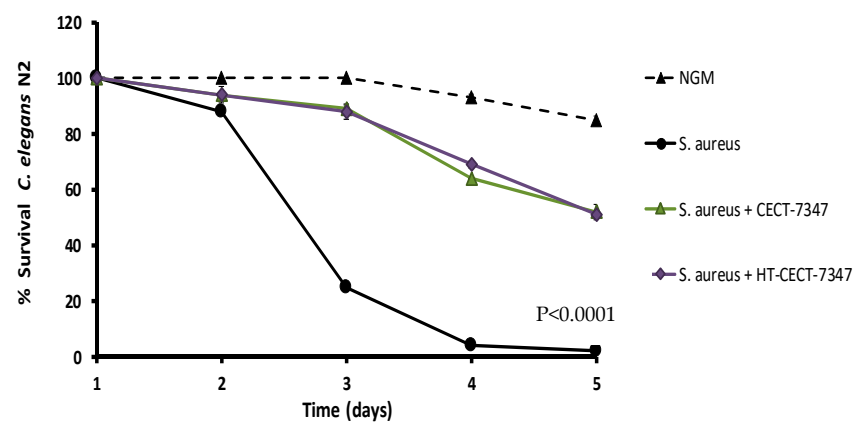

(a)

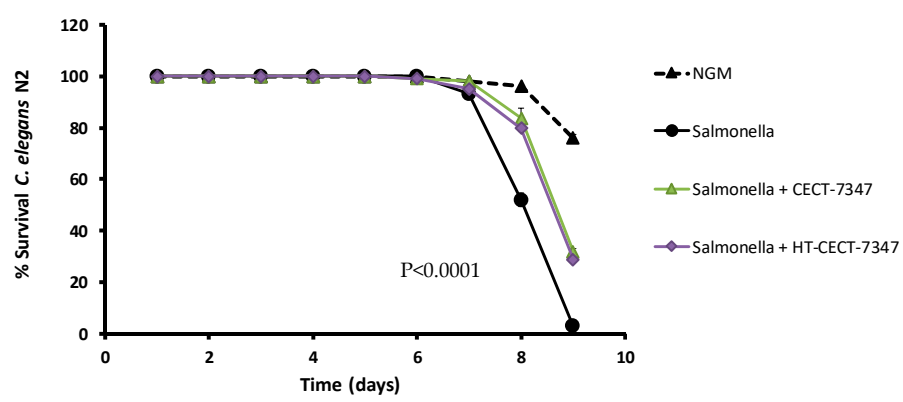

(b)

Figure 8. Effect of CECT 7347 and HT-CECT 7347 on resistance of C. elegans to S. aureus and S. enterica subsp. enterica serovar Typhimurium. (a) Worms fed with E. coli OP50 (control), S. aureus, and CECT 7347 or HT-CECT 7347 in the presence of the pathogen. Worms fed with B. longum cells (both live and heat-treated cells) were more resistant to infection $(p<0.0001)(\mathbf{b})$ Worms fed with E. coli OP50 (control), S. enterica subsp. enterica serovar Typhimurium, and CECT-7347 or HT-CECT 7347 in the presence of the pathogen. Worms fed with B. longum cells (both live and heat-treated cells) were more resistant to infection $(p<0.0001)$. Log Rank T-test was applied. Data are the average of two independent experiments ( $n=100 /$ condition).

\section{Discussion}

Disrupted intestinal barrier function triggers an inflammatory response, as increased permeability leads pathogens and toxins into tissues and blood stream, causing endotoxemia. Conversely, systemic inflammation impairs the epithelial barrier, cytokines and interleukins activating NF- $\mathrm{kB}$ signaling pathway that in turn induces TJ disassembly. These processes are typically characterized by oxidative stress, with excessive ROS production as host defense is weakened, and by markers of intestinal barrier damage, redox imbalance, and inflammation $[60,61]$.

Probiotic strains have been reported to help maintain the homeostasis of intestinal function, by regulating the expression of $\mathrm{TJ}$ proteins at cell boundaries, reducing adverse effects of pathogens, and protecting them from oxidative stress-induced damage, by scavenging ROS and/or preventing their formation while modulating inflammatory cascades $[9,31,34]$. Similarly, beneficial properties have been documented in non-viable probiotics, including anti-inflammatory, anti-pathogen adhesion, and gut barrier function attributes $[6,10,14,62]$. 
However, few studies report on protection against oxidative stress in postbiotics [31,33]. Indeed, few subcellular postbiotic fractions or heat-treated probiotic strains have been shown to exert antioxidant effects $[14,37,63]$. References for antioxidant postbiotics derived from Bifidobacteria, a genus of substantial ecological significance for digestive well-being, are even more limited $[33,64,65]$.

In this study, we have demonstrated how both living and heat-treated B. longum CECT-7347 cells resulted in higher survival rates of $C$. elegans following acute oxidative stress, while the live form increased lifespan. Interestingly, both effects seem mediated by DAF-16, the Forkhead family of transcription factors (FOXO) downstream insulin signaling pathway (IGF-1). In C. elegans, this is one of the main pathways involved in lifespan control, oxidative stress, regulation of immune response and defense against pathogen infection [66] These results further validate the previous report by Sugawara and coworkers, on a heatkilled B. longum strain, also suggesting a DAF-16 mechanism, independent of SKN-1 [37]. This observation contradicts previous findings for other probiotic species, describing a SKN-1-mediated, DAF-16-independent, mechanism [40,67]. Further analysis should be performed in order to validate alternative molecular modulators of DAF-16, such as the JNK pathway or parallel pathways like SKN1 via p38 MAPK pathway.

Furthermore, heat-treated CECT-7347 did not result in improved lifespan, unlike living CECT-7347. Further research should investigate the precise mechanism by which the living form, but not HT-CECT-7347, contributes to longevity and anti-aging properties in the worm model. However, it is worth noting that CECT-7347 is a butyric acid producer (Figure A2). Short-chain fatty acid (SCFA) butyric acid has been shown to extend C. elegans lifespan; therefore, we can hypothesize that this particular trait, which is unlikely to be preserved in the heat-treated form, contributes to the differential lifespan of CECT-7347-fed C. elegans.

Following previous observations in probiotic strains correlating anti-inflammatory phenotype with the capacity to alleviate oxidative stress in C. elegans through the DAF16 transcriptional factor, we investigated whether co-incubation with HT-CECT-7347 could attenuate the release of inflammatory IL- 8 upon TNF- $\alpha$ stimulation. Multiple studies have shown the impact of probiotic bacteria by attenuating IL-8 secretion in cytokine-stimulated cells, thus potentially contributing to the maintenance of intestinal homeostasis [68-72]. $\mathrm{NF}-\mathrm{KB}$ is a key regulator of the inducible expression of many genes involved in immune and inflammatory responses in the gut [73]. Its activation is strongly induced in the inflamed gut, with levels correlating significantly with the severity of intestinal inflammation [74]. Furthermore, in mammals, there is a direct link between signaling via longevity factors, such as FoxOs, and inhibition of NF-kB signaling [75]. Accordingly, our findings show a dose-dependent decrease in IL-8 production, mediated by the impaired NF-kB nuclear localization as a result of HT-CECT-7347 feeding. Therefore, according to our data, HTCECT-7347 has the potential to protect intestinal cells from an acute inflammatory response.

Protection against pathogens has also been described in heat-killed bacteria, mostly in Lactobacilli, capable of reducing the effects of the infection of pathogens such as enterotoxigenic E. coli, Salmonella, Campylobacter, and H. pylori, by enhancing the immune response and competing for gastrointestinal adhesion sites [14]. However, reports of inactivated bifidobacteria leading to enhanced resistance to pathogens are scarce [76,77]. In this study, we have shown how both living and heat-treated CECT-7347 reduce the lethality of both Gram positive (Salmonella) and Gram negative (S. aureus) pathogens in C. elegans. These results, together with its observed ability to increase longevity in a DAF-16 dependentmanner, would suggest an immune modulatory activity of the strain [78]. Whether this occurs by competitive exclusion of pathogen adhesion, and/or enhancement of innate defense mechanisms, has yet to be investigated.

As previously mentioned, in the context of inflammation and oxidative stress, support of TJ integrity is relevant to prevent or restore impaired gut barrier function. Interestingly, in a dose-dependent manner, HT-CECT-7347 was able to maintain the intestinal permeability upon MTX disruption at higher levels than its living counterpart CECT-7347. The toxic 
effects of MTX, a folate antagonist widely used in the treatment of cancer and autoimmune diseases, are well described, and include intestinal toxicity [79]. To ameliorate the secondary effects, different studies suggest the use of a reduced form of folate derivate, Leucovorin (LV), as a treatment to counteract the intestinal toxicity provoked by MTX (Huang et al. 2020). Bearing in mind the important role played by the microbiome on intestinal integrity, other approaches are based on the use of probiotics of Bifidobacterium genera, which can produce large amounts of active metabolites, including folate. We hypothesized that the production of a metabolite, like folate, could be responsible of the protective effect of strain B. longum CECT-7347 in C. elegans MTX-induced leaky gut. However, the fact that a greater effect was observed with the heat-treated strain would suggest that the underlying mechanism of action is a biomass component of the probiotic strain, rather than its metabolic activity. The effects have been correlated with increased zonulin expression, in agreement with previous findings for the live CECT-7347 strain [15]. Furthermore, our results also agree with observations of other B. longum strains, which report reduced MTX-induced intestinal damage in mice through decreased inflammation, as well as a reduction in Zoo-1 expression in intestinal tissue (Huang et al. 2020). Gut barrier integrity has been shown as a key factor, cause or consequence, in multiple conditions involving gut inflammation in their clinical presentations. Altered gut permeability has been linked with fibromyalgia, chronic fatigue, neurodegeneration processes [80-82], arthritis [83], and metabolic disorders [84], among others. Furthermore, skin alterations have also been linked with gut permeability, correlating with disease severity in the case of psoriasis [85]. Furthermore, in some of the studies, restoration of the gut barrier was also linked to clinical improvement $[80,83,84]$. In this context, ingredients preserving intestinal permeability have the potential to positively contribute to well-being in conditions with underlying inflammatory digestive origin. In this context, CECT 7347 and HT-CECT 7347 may have a significant role to be further investigated in future studies.

\section{Conclusions}

In summary, this study investigated the properties of HT-CECT-7347, the heat-treated form of probiotic strain CECT-7347, and compared it with its live form. Results highlight its capacity to counter-balance oxidative stress damage, together with other stressors related to intestinal inflammation, including pro-inflammatory mediators and gut-barrier disruptors. The results obtained are consistent with the anti-inflammatory, gut-barrier protective effects previously described for the live strain $[15,25]$. The fact that most of the functional properties of this strain are preserved in the heat-treated form provides further information on postbiotics, supporting the notion that non-Lactobacilli probiotic strains can remain biologically active despite being non-viable. Future research will explore the specific mechanisms through which HT-CECT-7347 exerts its functionality, and also investigate its effects in higher animal models, targeting immune function support and gut health. The availability of heat-stable postbiotics, such as HT-CECT-7347, is essential to broaden the range of applications of functional microbial solutions, enabling delivery in challenging matrixes and facilitating logistics in extreme environmental conditions.

Author Contributions: Supervision, conceptualization, and methodology: P.M., B.A., D.R., M.T.; experimental validation: S.L., N.G., F.B. (C. elegans), V.N. and P.O. (cell cultures). Visualization and formal analysis: F.B., B.A., S.L., A.R. Writing—original draft preparation: P.M., B.A., M.T. Writingreview and editing: P.M., B.A., D.R., E.C., A.R., M.T. All authors have read and agreed to the published version of the manuscript.

Funding: This research received no external funding.

Institutional Review Board Statement: Not applicable.

Informed Consent Statement: Not applicable.

Data Availability Statement: The data presented in this study is contained within the article.

Conflicts of Interest: All authors are employees of Archer Daniels Midland. 


\section{Appendix A}

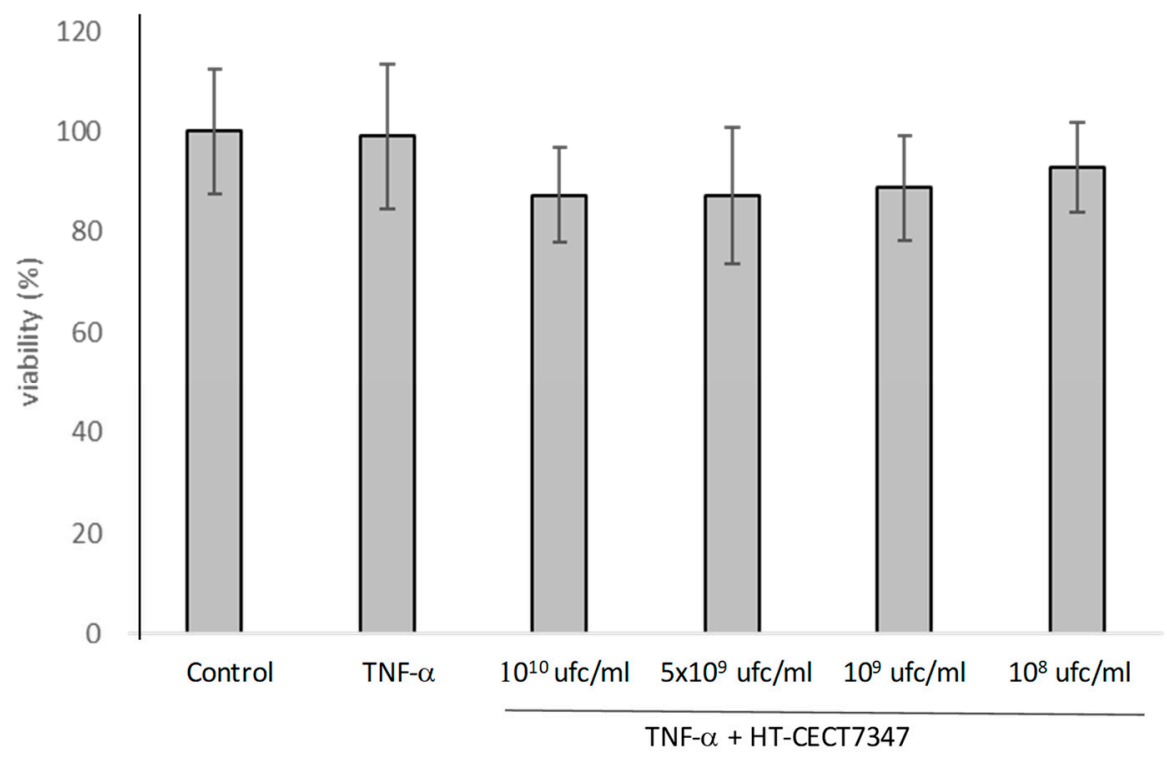

Figure A1. Maintenance of cell viability upon TNF- $\alpha$ stimulation in the different samples in which IL-8 production has been quantified, corresponding to Figure 4 in the main text.

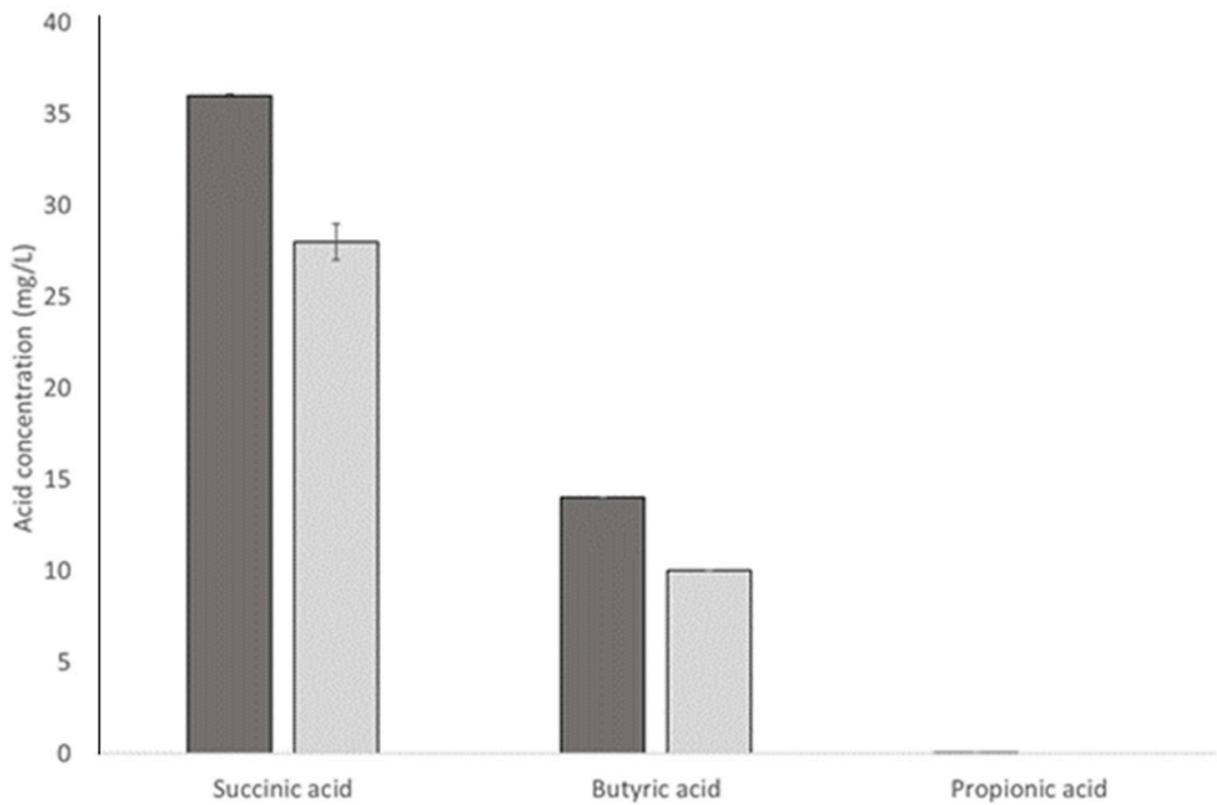

Figure A2. Succinic, butyric and propionic acid production by B. longum CECT7347, determined by HPLC in culture supernatant in MRS medium, upon 24 and $48 \mathrm{~h}$ of growth.

\section{References}

1. World Health Organization; Food and Agriculture Organization of the United Nations. Probiotics in Food: Health and Nutritional Properties and Guidelines for Evaluation; WHO/FAO: Rome, Italy, 2006; ISBN 0254-4725.

2. Hill, C.; Guarner, F.; Reid, G.; Gibson, G.R.; Merenstein, D.J.; Pot, B.; Morelli, L.; Canani, R.B.; Flint, H.J.; Salminen, S.; et al. Expert consensus document. The International Scientific Association for Probiotics and Prebiotics consensus statement on the scope and appropriate use of the term probiotic. Nat. Rev. Gastroenterol. Hepatol. 2014, 11, 506-514. [CrossRef]

3. Soccol, C.R.; de Souza Vandenberghe, L.P.; Spier, M.R.; Medeiros, A.B.P.; Yamaguishi, C.T.; Lindner, J.D.D.; Pandey, A.; ThomazSoccol, V. The potential of probiotics: A review. Food Technol. Biotechnol. 2010, 48, 413-434. 
4. Langella, P.; Guarner, F.; Martín, R. Editorial: Next-generation probiotics: From commensal bacteria to novel drugs and food supplements. Front. Microbiol. 2019, 10, 1973. [CrossRef] [PubMed]

5. Sanders, M.E.; Merenstein, D.J.; Reid, G.; Gibson, G.R.; Rastall, R.A. Probiotics and prebiotics in intestinal health and disease: From biology to the clinic. Nat. Rev. Gastroenterol. Hepatol. 2019, 16, 605-616. [CrossRef] [PubMed]

6. Zolkiewicz, J.; Marzec, A.; Ruszczynski, M.; Feleszko, W. Postbiotics-A Step Beyond Pre- and Probiotics. Nutrients 2020, 12, 2189. [CrossRef] [PubMed]

7. Wegh, C.A.M.; Geerlings, S.Y.; Knol, J.; Roeselers, G.; Belzer, C. Postbiotics and their potential applications in early life nutrition and beyond. Int. J. Mol. Sci. 2019, 20, 4673. [CrossRef] [PubMed]

8. Balaguer, F.; Enrique, M.; Llopis, S.; Barrena, M.; Navarro, V.; Alvarez, B.; Chenoll, E.; Ramón, D.; Tortajada, M.; Martorell, P. Lipoteichoic acid from Bifidobacterium animalis subsp. lactis BPL1: A novel postbiotic that reduces fat deposition via IGF-1 pathway. Microbial. Biotechnol. 2021. [CrossRef]

9. Nataraj, B.H.; Ali, S.A.; Behare, P.V.; Yadav, H. Postbiotics-parabiotics: The new horizons in microbial biotherapy and functional foods. Microb. Cell Fact. 2020, 19, 168. [CrossRef]

10. De Almada, C.N.; Almada, C.N.; Martinez, R.C.R.; SantAna, A.S. Paraprobiotics: Evidences on their ability to modify biological responses, inactivation methods and perspectives on their application in foods. Trends Food Sci. Technol. 2016, 58, 96-114. [CrossRef]

11. Collado, M.C.; Vinderola, G.; Salminen, S. Postbiotics: Facts and open questions. A position paper on the need for a consensus definition. Benef. Microbes 2019, 10, 711-719. [CrossRef]

12. Aguilar-Toalá, J.E.; Garcia-Varela, R.; Garcia, H.S.; Mata-Haro, V.; González-Córdova, A.F.; Vallejo-Cordoba, B.; HernándezMendoza, A. Postbiotics: An evolving term within the functional foods field. Trends Food Sci. Technol. 2018, 75, 105-114. [CrossRef]

13. Cuevas-González, P.F.; Liceaga, A.M.; Aguilar-Toalá, J.E. Postbiotics and paraprobiotics: From concepts to applications. Food Res. Int. 2020, 136, 109502. [CrossRef]

14. Pique, N.; Berlanga, M.; Minana-Galbis, D. Health benefits of heat-killed (tyndallized) probiotics: An overview. Int. J. Mol. Sci. 2019, 20, 2534. [CrossRef] [PubMed]

15. De Palma, G.; Kamanova, J.; Cinova, J.; Olivares, M.; Drasarova, H.; Tuckova, L.; Sanz, Y. Modulation of phenotypic and functional maturation of dendritic cells by intestinal bacteria and gliadin: Relevance for celiac disease. J. Leukoc. Biol. 2012, 92, 1043-1054. [CrossRef] [PubMed]

16. Izquierdo, E.; Medina, M.; Ennahar, S.; Marchioni, E.; Sanz, Y. Resistance to simulated gastrointestinal conditions and adhesion to mucus as probiotic criteria for Bifidobacterium longum strains. Curr. Microbiol. 2008, 56, 613-618. [CrossRef]

17. Olivares, M.; Castillejo, G.; Varea, V.; Sanz, Y. Double-blind, randomised, placebo-controlled intervention trial to evaluate the effects of Bifidobacterium longum CECT 7347 in children with newly diagnosed coeliac disease. Br. J. Nutr. 2014, 112, 30-40. [CrossRef] [PubMed]

18. Di Pierro, F.; Bergomas, F.; Marraccini, P.; Ingenito, M.R.; Ferrari, L.; Vigna, L. Pilot study on non-celiac gluten sensitivity: Effects of Bifidobacterium longum ES1 co-administered with a gluten-free diet. Minerva Gastroenterol. Dietol. 2020, 66, 187-193. [CrossRef] [PubMed]

19. Codoñer, F.M.; Ramírez-Bosca, A.; Climent, E.; Carrión-Gutierrez, M.; Guerrero, M.; Pérez-Orquín, J.M.; de la Parte, J.H.; Genovés, S.; Ramón, D.; Navarro-López, V.; et al. Gut microbial composition in patients with psoriasis. Sci. Rep. 2018, 8, 3812. [CrossRef]

20. Navarro-López, V.; Ramírez-Boscá, A.; Ramón-Vidal, D.; Ruzafa-Costas, B.; Genovés-Martínez, S.; Chenoll-Cuadros, E.; CarriónGutiérrez, M.; de la Parte, J.H.; Prieto-Merino, D.; Codoñer-Cortés, F.M. Effect of oral administration of a mixture of probiotic strains on SCORAD index and use of topical steroids in young patients with moderate atopic dermatitis: A randomized clinical trial. JAMA Dermatol. 2018, 154, 37-43. [CrossRef]

21. Tremellen, K. Gut endotoxin leading to a decline in Gonadal function (GELDING) - A novel theory for the development of late onset hypogonadism in obese men. Basic Clin. Androl. 2016, 26, 7. [CrossRef]

22. Valcarce, D.G.; Genovés, S.; Riesco, M.F.; Martorell, P.; Herráez, M.P.; Ramón, D.; Robles, V. Probiotic administration improves sperm quality in asthenozoospermic human donors. Benef. Microbes 2017, 8, 193-206. [CrossRef] [PubMed]

23. Corsi, A.K.; Wightman, B.; Chalfie, M. A transparent window into biology: A primer on Caenorhabditis elegans. Genetics 2015, 200, 387-407. [CrossRef]

24. Martorell, P.; Bataller, E.; Llopis, S.; Gonzalez, N.; Alvarez, B.; Montón, F.; Ortiz, P.; Ramón, D.; Genovés, S. A cocoa peptide protects Caenorhabditis elegans from oxidative stress and $\beta$-amyloid peptide toxicity. PLoS ONE 2013, 8, e63283. [CrossRef] [PubMed]

25. Medina, M.; de Palma, G.; Ribes-Koninckx, C.; Calabuig, M.; Sanz, Y. Bifidobacterium strains suppress in vitro the pro-inflammatory milieu triggered by the large intestinal microbiota of coeliac patients. J. Inflamm. (Lond.) 2008, 5, 19. [CrossRef] [PubMed]

26. Martorell, P.; Forment, J.V.; de Llanos, R.; Montón, F.; Llopis, S.; González, N.; Genovés, S.; Cienfuegos, E.; Monzó, H.; Ramón, D. Use of Saccharomyces cerevisiae and Caenorhabditis elegans as model organisms to study the effect of cocoa polyphenols in the resistance to oxidative stress. J. Agric. Food Chem. 2011, 59, 2077-2085. [CrossRef]

27. Kim, Y.; Mylonakis, E. Caenorhabditis elegans immune conditioning with the probiotic bacterium Lactobacillus acidophilus strain NCFM enhances gram-positive immune responses. Infect. Immun. 2012, 80, 2500-2508. [CrossRef]

28. Ikeda, T.; Yasui, C.; Hoshino, K.; Arikawa, K.; Nishikawa, Y. Influence of lactic acid bacteria on longevity of Caenorhabditis elegans and host defense against Salmonella enterica serovar enteritidis. Appl. Environ. Microbiol. 2007, 73, 6404-6409. [CrossRef]

29. Kong, C.; Yehye, W.A.; Abd Rahman, N.; Tan, M.W.; Nathan, S. Discovery of potential anti-infectives against Staphylococcus aureus using a Caenorhabditis elegans infection model. BMC Complement. Altern. Med. 2014, 14, 4. [CrossRef] 
30. Zhao, Y.; Yu, X.; Jia, R.; Yang, R.; Rui, Q.; Wang, D. Lactic acid bacteria protects Caenorhabditis elegans from toxicity of graphene oxide by maintaining normal intestinal permeability under different genetic backgrounds. Sci. Rep. 2015, 5, 17233. [CrossRef]

31. Wang, Y.; Wu, Y.; Wang, Y.; Xu, H.; Mei, X.; Yu, D.; Wang, Y.; Li, W. Antioxidant properties of probiotic bacteria. Nutrients 2017, 9, 521. [CrossRef]

32. Jang, H.J.; Song, M.W.; Lee, N.K.; Paik, H.D. Antioxidant effects of live and heat-killed probiotic Lactobacillus plantarum Ln1 isolated from kimchi. J. Food Sci. Technol. 2018, 55, 3174-3180. [CrossRef]

33. Mishra, V.; Shah, C.; Mokashe, N.; Chavan, R.; Yadav, H.; Prajapati, J. Probiotics as potential antioxidants: A systematic review. J. Agric. Food Chem. 2015, 63, 3615-3626. [CrossRef] [PubMed]

34. Feng, T.; Wang, J. Oxidative stress tolerance and antioxidant capacity of lactic acid bacteria as probiotic: A systematic review. Gut Microbes 2020, 12, 1801944. [CrossRef]

35. Grompone, G.; Martorell, P.; Llopis, S.; González, N.; Genovés, S.; Mulet, A.P.; Fernández-Calero, T.; Tiscornia, I.; Bollati-Fogolín, M.; Chambaud, I.; et al. Anti-inflammatory Lactobacillus rhamnosus CNCM I-3690 strain protects against oxidative stress and increases lifespan in Caenorhabditis elegans. PLoS ONE 2012, 7, e52493.

36. Martorell, P.; Llopis, S.; González, N.; Chenoll, E.; López-Carreras, N.; Aleixandre, A.; Chen, Y.; Karoly, E.D.; Ramón, D.; Genovés, S. Probiotic strain Bifidobacterium animalis subsp. lactis CECT 8145 reduces fat content and modulates lipid metabolism and antioxidant response in Caenorhabditis elegans. J. Agric. Chem. 2016, 64, 3462-3472. [CrossRef] [PubMed]

37. Sugawara, T.; Sakamoto, K. Killed Bifidobacterium longum enhanced stress tolerance and prolonged life span of Caenorhabditis elegans via DAF-16. Br. J. Nutr. 2018, 120, 872-880. [CrossRef] [PubMed]

38. Garsin, D.A.; Villanueva, J.M.; Begun, J.; Kim, D.H.; Sifri, C.D.; Calderwood, S.B.; Ruvkun, G.; Ausubel, F.M. Long-lived C. elegans daf-2 mutants are resistant to bacterial pathogens. Science 2003, 300, 1921. [CrossRef] [PubMed]

39. Zheng, J.; Greenway, F.L. Caenorhabditis elegans as a model for obesity research. Int. J. Obes. (Lond.) 2012, 36, 186-194. [CrossRef] [PubMed]

40. Nakagawa, H.; Shiozaki, T.; Kobatake, E.; Hosoya, T.; Moriya, T.; Sakai, F.; Taru, H.; Miyazaki, T. Effects and mechanisms of prolongevity induced by Lactobacillus gasseri SBT2055 in Caenorhabditis elegans. Aging Cell 2016, 15, 227-236. [CrossRef]

41. Luyten, W.; Antal, P.; Braeckman, B.P.; Bundy, J.; Cirulli, F.; Fang-Yen, C.; Fuellen, G.; Leroi, A.; Liu, Q.; Martorell, P.; et al. Ageing with elegans: A research proposal to map healthspan pathways. Biogerontology 2016, 17, 771-782. [CrossRef] [PubMed]

42. Murphy, C.T.; McCarroll, S.A.; Bargmann, C.I.; Fraser, A.; Kamath, R.S.; Ahringer, J.; Li, H.; Kenyon, C. Genes that act downstream of DAF-16 to influence the lifespan of Caenorhabditis elegans. Nature 2003, 424, 277-283. [CrossRef]

43. Kim, D.H.; Feinbaum, R.; Alloing, G.; Emerson, F.E.; Garsin, D.A.; Inoue, H.; Tanaka-Hino, M.; Hisamoto, N.; Matsumoto, K.; Tan, M.W.; et al. A conserved p38 MAP kinase pathway in Caenorhabditis elegans innate immunity. Science 2002, 297, 623-626. [CrossRef]

44. Roselli, M.; Schifano, E.; Guantario, B.; Zinno, P.; Uccelletti, D.; Devirgiliis, C. Caenorhabditis elegans and probiotics interactions from a prolongevity perspective. Int. J. Mol. Sci. 2019, 20, 5020. [CrossRef]

45. Lammers, K.M.; Jansen, J.; Bijlsma, P.B.; Ceska, M.; Tytgat, G.N.; Laboisse, C.L.; van Deventer, S.J. Polarised interleukin 8 secretion by HT 29/19A cells. Gut 1994, 35, 338-342. [CrossRef] [PubMed]

46. Warhurst, A.C.; Hopkins, S.J.; Warhurst, G. Interferon gamma induces differential upregulation of alpha and beta chemokine secretion in colonic epithelial cell lines. Gut 1998, 42, 208-213. [CrossRef]

47. Rahman, M.M.; McFadden, G. Modulation of NF-kB signalling by microbial pathogens. Nat. Rev. Microbiol. 2011, 9, 291-306. [CrossRef]

48. Hsu, H.; Xiong, J.; Goeddel, D.V. The TNF receptor 1-associated protein TRADD signals cell death and NF-kappa B activation. Cell 1995, 81, 495-504. [CrossRef]

49. Neurath, M.F.; Becker, C.; Barbulescu, K. Role of NF-kappaB in immune and inflammatory responses in the gut. Gut 1998, 43, 856-860. [CrossRef]

50. Viatour, P.; Merville, M.P.; Bours, V.; Chariot, A. Phosphorylation of NF-kappaB and IkappaB proteins: Implications in cancer and inflammation. Trends Biochem. Sci. 2005, 30, 43-52. [CrossRef]

51. Petrof, E.O.; Kojima, K.; Ropeleski, M.J.; Musch, M.W.; Tao, Y.; de Simone, C.; Chang, E.B. Probiotics inhibit nuclear factor-kappaB and induce heat shock proteins in colonic epithelial cells through proteasome inhibition. Gastroenterology 2004, 127, $1474-1487$. [CrossRef] [PubMed]

52. Zhang, J.; Zhao, X.; Jiang, Y.; Zhao, W.; Guo, T.; Cao, Y.; Teng, J.; Hao, X.; Zhao, J.; Yang, Z. Antioxidant status and gut microbiota change in an aging mouse model as influenced by exopolysaccharide produced by Lactobacillus plantarum YW11 isolated from Tibetan kefir. J. Dairy Sci. 2017, 100, 6025-6041. [CrossRef]

53. Wu, Q.; Yin, L.; Li, X.; Tang, M.; Zhang, T.; Wang, D. Contributions of altered permeability of intestinal barrier and defecation behavior to toxicity formation from graphene oxide in nematode Caenorhabditis elegans. Nanoscale 2013, 5, 9934-9943. [CrossRef]

54. Song, D.; Shi, B.; Xue, H.; Li, Y.; Yang, X.; Yu, B.; Xu, Z.; Liu, F.; Li, J. Confirmation and prevention of intestinal barrier dysfunction and bacterial translocation caused by methotrexate. Dig. Dis. Sci. 2006, 51, 1549-1556. [CrossRef] [PubMed]

55. Huang, X.; Fang, Q.; Rao, T.; Zhou, L.; Zeng, X.; Tan, Z.; Chen, L.; Ouyang, D. Leucovorin ameliorated methotrexate induced intestinal toxicity via modulation of the gut microbiota. Toxicol Appl. Pharmacol. 2020, 391, 114900. [CrossRef]

56. Aballay, A.; Yorgey, P.; Ausubel, F.M. Salmonella typhimurium proliferates and establishes a persistent infection in the intestine of Caenorhabditis elegans. Curr. Biol. 2000, 10, 1539-1542. [CrossRef] 
57. Labrousse, A.; Chauvet, S.; Couillault, C.; Kurz, C.L.; Ewbank, J.J. Caenorhabditis elegans is a model host for Salmonella typhimurium. Curr. Biol. 2000, 10, 1543-1545. [CrossRef]

58. Sifri, C.D.; Begun, J.; Ausubel, F.M.; Calderwood, S.B. Caenorhabditis elegans as a model host for Staphylococcus aureus pathogenesis. Infect. Immun. 2003, 71, 2208-2217. [CrossRef] [PubMed]

59. Alegado, R.A.; Campbell, M.C.; Chen, W.C.; Slutz, S.S.; Tan, M.W. Characterization of mediators of microbial virulence and innate immunity using the Caenorhabditis elegans host-pathogen model. Cell Microbiol. 2003, 5, 435-444. [CrossRef] [PubMed]

60. Hietbrink, F.; Besselink, M.G.H.; Renooij, W.; de Smet, M.B.M.; Draisma, A.; van der Hoeven, H.; Pickkers, P. Systemic inflammation increases intestinal permeability during experimental human endotoxemia. Shock 2009, 32, 374-378. [CrossRef] [PubMed]

61. Nathan, C. Points of control in inflammation. Nature 2002, 420, 846-852. [CrossRef] [PubMed]

62. Vallejo-Cordoba, B.; Castro-Lopez, C.; Garcia, H.S.; Gonzalez-Cordova, A.F.; Hernandez-Mendoza, A. Postbiotics and paraprobiotics: A review of current evidence and emerging trends. Adv. Food Nutr. Res. 2020, 94, 1-34.

63. De Marco, S.; Sichetti, M.; Muradyan, D.; Piccioni, M.; Traina, G.; Pagiotti, R.; Pietrella, D. Probiotic cell-free supernatants exhibited anti-inflammatory and antioxidant activity on human gut epithelial cells and macrophages stimulated with LPS. Evid. Based Complement. Altern. Med. 2018, 2018, 1756308. [CrossRef]

64. Amaretti, A.; di Nunzio, M.; Pompei, A.; Raimondi, S.; Rossi, M.; Bordoni, A. Antioxidant properties of potentially probiotic bacteria: In vitro and in vivo activities. Appl. Microbiol. Biotechnol. 2013, 97, 809-817. [CrossRef]

65. Sarkar, A.; Mandal, S. Bifidobacteria-insight into clinical outcomes and mechanisms of its probiotic action. Microbiol. Res. 2016, 192, 159-171. [CrossRef] [PubMed]

66. Kurz, C.L.; Ewbank, J.J. Caenorhabditis elegans: An emerging genetic model for the study of innate immunity. Nat. Rev. Genet 2003, 4, 380-390. [CrossRef]

67. Komura, T.; Ikeda, T.; Yasui, C.; Saeki, S.; Nishikawa, Y. Mechanism underlying prolongevity induced by bifidobacteria in Caenorhabditis elegans. Biogerontology 2013, 14, 1-73. [CrossRef]

68. Imaoka, A.; Shima, T.; Kato, K.; Mizuno, S.; Uehara, T.; Matsumoto, S.; Setoyama, H.; Hara, T.; Umesaki, Y. Anti-inflammatory activity of probiotic Bifidobacterium: Enhancement of IL-10 production in peripheral blood mononuclear cells from ulcerative colitis patients and inhibition of IL-8 secretion in HT-29 cells. World J. Gastroenterol. 2008, 14, 2511-2516. [CrossRef]

69. Choi, C.H.; Kim, T.I.; Lee, S.K.; Yang, K.M.; Kim, W.H. Effect of Lactobacillus GG and conditioned media on IL-1beta-induced IL-8 production in Caco-2 cells. Scand. J. Gastroenterol. 2008, 43, 938-947. [CrossRef]

70. Ren, D.Y.; Li, C.; Qin, Y.Q.; Yin, R.L.; Du, S.W.; Ye, F.; Liu, H.F.; Wang, M.P.; Sun, Y.; Li, X.; et al. Lactobacilli reduce chemokine IL-8 production in response to TNF- $\alpha$ and Salmonella challenge of Caco-2 cells. Biomed. Res. Int. 2013, 2013, 925219. [CrossRef] [PubMed]

71. Bai, A.P.; Ouyang, Q.; Zhang, W.; Wang, C.H.; Li, S.F. Probiotics inhibit TNF-alpha-induced interleukin-8 secretion of HT29 cells. World J. Gastroenterol. 2004, 10, 455-457. [CrossRef]

72. Ma, D.; Forsythe, P.; Bienenstock, J. Live Lactobacillus rhamnosus [corrected] is essential for the inhibitory effect on tumor necrosis factor alpha-induced interleukin-8 expression. Infect. Immun. 2004, 72, 5308-5314. [CrossRef]

73. Neurath, M.F.; Fuss, I.; Schürmann, G.; Pettersson, S.; Arnold, K.; Müller-Lobeck, H.; Strober, W.; Herfarth, C.; Büschenfelde, K.H. Cytokine gene transcription by NF-kappa B family members in patients with inflammatory bowel disease. Ann. N. Y. Acad. Sci. 1998, 859, 149-159. [CrossRef]

74. Jobin, C.; Sartor, R.B. NF-kappaB signaling proteins as therapeutic targets for inflammatory bowel diseases. Inflamm. Bowel Dis. 2000, 6, 206-213. [CrossRef]

75. Salminen, A.; Ojala, J.; Huuskonen, J.; Kauppinen, A.; Suuronen, T.; Kaarniranta, K. Interaction of aging-associated signaling cascades: Inhibition of NF-kappaB signaling by longevity factors FoxOs and SIRT1. Cell Mol. Life Sci. 2008, 65, 1049-1058. [CrossRef]

76. Shkarupeta, M.M.; Korshunov, V.M.; Savenkova, V.T.; Pinegin, B.V. Influence of the oral administration of indigenous microorganisms on the resistance of mice to Salmonella infection. Zhurnal Mikrobiologii, Epidemiologii i Immunobiologii 1988, 7, 46-50.

77. Schwendicke, F.; Horb, K.; Kneist, S.; Dörfer, C.; Paris, S. Effects of heat-inactivated Bifidobacterium BB12 on cariogenicity of Streptococcus mutans in vitro. Arch. Oral Biol. 2014, 59, 1384-1390. [CrossRef]

78. Engelmann, I.; Pujol, N. Innate immunity in C. elegans. Adv. Exp. Med. Biol. 2010, 708, 105-121.

79. Howard, S.C.; McCormick, J.; Pui, C.H.; Buddington, R.K.; Harvey, R.D. Preventing and managing toxicities of high-dose methotrexate. Oncologist 2016, 21, 1471-1482. [CrossRef]

80. Maes, M.; Leunis, J.C. Normalization of leaky gut in chronic fatigue syndrome (CFS) is accompanied by a clinical improvement: Effects of age, duration of illness and the translocation of LPS from gram-negative bacteria. Neuro Endocrinol. Lett. 2008, 29, 902-910. [PubMed]

81. Goebel, A.; Buhner, S.; Schedel, R.; Lochs, H.; Sprotte, G. Altered intestinal permeability in patients with primary fibromyalgia and in patients with complex regional pain syndrome. Rheumatology 2008, 47, 1223-1227. [CrossRef] [PubMed]

82. Kowalski, K.; Mulak, A. Brain-gut-microbiota axis in Alzheimer's disease. J. Neurogastroenterol. Motil. 2019, 25, 48-60. [CrossRef] [PubMed]

83. Tajik, N.; Frech, M.; Schulz, O.; Schälter, F.; Lucas, S.; Azizov, V.; Dürholz, K.; Steffen, F.; Omata, Y.; Rings, A.; et al. Targeting zonulin and intestinal epithelial barrier function to prevent onset of arthritis. Nat. Commun. 2020, 11, 1995. [CrossRef] [PubMed] 
84. Pasini, E.; Corsetti, G.; Assanelli, D.; Testa, C.; Romano, C.; Dioguardi, F.S.; Aquilani, R. Effects of chronic exercise on gut microbiota and intestinal barrier in human with type 2 diabetes. Minerva Med. 2019, 110, 3-11. [CrossRef] [PubMed]

85. Sikora, M.; Stec, A.; Chrabaszcz, M.; Knot, A.; Waskiel-Burnat, A.; Rakowska, A.; Olszewska, M.; Rudnicka, L. Gut microbiome in psoriasis: An updated review. Pathogens 2020, 9, 463. [CrossRef] 